\title{
Process Management Challenges in Swedish Public Sector: A Bottom Up Initiative
}

\author{
Carl-Mikael Lönn and Elin Uppström \\ Department of Computer and Systems Sciences, Stockholm University, Sweden \\ $\{\mathrm{cml}$, elinu $\}$ dsv.su.se
}

\begin{abstract}
Public administration is under pressure to work more effectively and increase effectiveness with regards to internal administrative processes as well as level of service towards citizens. This paper identifies process management challenges encountered in Swedish municipalities and provides concrete examples of consequences of these challenges by using a bottom up approach. It is done by using a common public service process and a mobile solution as platform for discussions with municipal officials working with the process. To categorise the challenges they are grouped into six core categories of business process management, which provide a picture of challenges that municipalities face today. Results show that Swedish municipalities face challenges in all categories and that it was not possible to design a generic process for the analysed service. To initiate work with improving process maturity in local governments the bottom up approach used was found successful.
\end{abstract}

Keywords: Process management, public administration processes, e-government.

\section{Introduction}

The public sector is struggling to become more effective. A driving vision to accomplish this goal is articulated as e-government and refers to improving public sector by rationalizing administration and improving the information and quality of services to citizens [1]. E-government utilizes information and communication technology to transform public administrations structures and processes [2] to increase efficiency and effectiveness. Sweden is considered as being in the forefront of e-government and is one of the highest ranked countries in [3] e-government development index. There are many policies and guidelines communicated from higher-level authorities that underline the importance of improved process management and increased collaboration in public sector [4-8].

With a total of 290 municipalities in Sweden the municipal government stands for $70 \%$ of the total public administration and is thereby considered a very important part in the realization of the e-government vision [5]. Swedish municipalities are autonomous and therefore choose to govern their own e-government initiatives; however they still have to comply with the same laws, policies and guidelines. 
This paper builds from experiences from a research project aiming to develop a fully integrated mobile complaint and problem reporting system (CPR system) [9]. In the project, processes for management of complaint and problems in Swedish municipalities were analysed with the aim to design a generic process model to be used in the new CPR system.

The objective of this paper is to highlight the process management related challenges encountered in the work with the municipalities. This objective is guided by the following research question: Which challenges do municipalities face in their process management? A bottom up approach is used were the complaint and problem management process and the CPR system is used as a platform for discussion and to identify process management related challenges.

There are many well-known and investigated benefits from working according to process-logic [10-11]. Research focusing on process challenges for the Swedish public sector has limited empirical foundation. This paper presents process challenges in the Swedish public sector from the view of the people working with the processes and by the researchers' analysis of the processes. It unpacks the challenges by giving concrete examples of how these challenges leads to inefficiencies in the daily work of municipal workers.

The challenges are analysed from a business process management (BPM) perspective by categorisation of the challenges according to [12] "six core elements of BPM". The paper contributes with a clear view of current challenges encountered within municipalities and what needs to be addressed in their process management work.

The paper is organized as follows: The next section gives a description of related research. Section 3 describes the research method and data collection techniques used. Section 4 presents the results and section 5 concludes the paper and directions for future work are presented.

\section{Previous Research}

\subsection{Process Management}

Business processes describes how business functions and they are central in Business Process Management [13]. Business process management (BPM) encompasses knowledge and practices from several areas [12] thereby creating a holistic management approach to business processes. [14, p. 4] defines Business process management as "supporting business processes using methods, techniques, and software to design, enact, control, and analyse operational processes involving humans, organizations, applications, documents and other sources of information". The objective with business process management is to improve the performance of organizations by making them more effective and reduce costs. This is enabled by constantly analysing and improving business processes. Improving the quality of public sector business processes can for example be done with the help of verifications tools [15-16]. BPM promotes agility and flexibility in which organizations can quicker adapt to changing market conditions [17]. Since BPM is a holistic management approach it includes all 
phases in a business process lifecycle. The BPM lifecycle proposed by [14] contains the phases design, configuration, enactment and diagnosis.

[12] Identifies "six core elements of BPM" that organizations need to regard in order to succeed with BPM: strategic alignment, governance, methods, information technology, people and culture. The goal with strategic alignment is to promote business performance by harmonizing organisational priorities and business processes. BPM governance handles roles and responsibilities at different levels of BPM. Also important in BPM governance is the decision making and reward processes that have impact on process associated actions. Methods related to BPM are tools and techniques that facilitate actions throughout all different stages of a process lifecycle, process projects and programs within an organization. Information technology relate to hardware, software and information systems that are aimed at supporting BPM. An example is process aware systems. People are the BPM knowledge within the human capital of an organization that constantly improves and applies their process abilities and knowledge to improve business performances. Culture has a strong influence on BPM achievements and it concerns attitudes and behaviors formed by mutual values and beliefs regarding process orientations. [12]

\subsection{Business Process Management Challenges}

To the researchers knowledge there is limited empirical research that highlights process management challenges that Swedish municipalities face. Research on process management challenges has been made in other countries and for other domains. [18] Reports on BPM issues from industry identified by conducting a focus group study with participants from several different Australian organisations. BPM issues and challenges that organizations in Australia face are presented and grouped in three high level categories: Strategic, Tactical and Operational. Examples of identified strategic challenges are shortage of governance and management support. At the tactical level examples of challenges are shortages of expertise, coordination, BPM understanding, visibility and standardization. Operational challenges examples are shortages of technology capability, integration and tools for holistic BPM. [19] and [20] are two related studies to the [18] study that report upon BPM challenges and group them after Strategic, Tactical and Operational challenges. [19] Reports BPM challenges identified through interviews with domain expert from the industry and [20] reports BPM challenges identified through interviews with BPM vendors. [21] Reports on experience from implementing process management in three private organisations in Sweden and calls for further research in this area.

There are studies focusing on process management related challenges in the public sector. [22] Explore process management and integration issues in a local council in the United Kingdom. Through a case study approach they study a public service process (the student loan application process) by conducting semi-structured interviews with four local authority staff, one representative from a partner organization and one citizen. In their research they identify technical and organizational challenges and the most important challenge for the local council was shortage of coordination and integration between the different stakeholders. There are also studies that 
investigate challenges in limited parts of BPM, for example business process modelling challenges and issues studied by [23] and challenges related to BPM methods studied by [24].

More recent studies investigate limited parts of BPM in different countries. [25] Investigates success factors and obstacles affecting BPM governance in local governments in Brazil. Main obstacles identified are lack of competence, BPM awareness and a non-process oriented culture. [26] States that local government in Germany lack BPM capabilities and therefore have problems with adjusting to a constantly changing environment and that they are under a financial pressure. [27] Presents an initiative on configurable process models and reports on difficulties for a municipality in Sweden to fully utilize the configurable approach due to a number of reasons connected to low process maturity.

\section{$3 \quad$ Research Method}

To answer the research question a case study research has been conducted. Case study research is a studying "a contemporary phenomenon within a real life context when the boundary between the phenomenon and its context is not clearly evident" [29, p. 13]. Case studies can be used in descriptive and exploratory research [28].

In this study the contemporary phenomenon is process management and the context is complaints and problem management within Swedish municipalities. The researchers have studied the phenomenon through the context of complaint and management handling at five different municipalities, thus following the case study methodology of viewing a phenomenon as tightly bound with the context were it is studied. Challenges related to process management are captured through the participants' descriptions of their view of the complaints and problem management process and the researcher's findings from being active participants in the analysis of the processes and when designing a generic process model.

The complaint and problem management process is a suitable process to study since almost all municipalities in Sweden offer the service; it is also one of the most common e-service provided by Swedish municipalities [30]. Different units within a municipality handle complaints and problems reported by citizens and the handling of complaints and problems often spans over several administrative units.

\subsection{Data Collection and Analysis}

To collect data ten workshops with municipalities were performed, all municipalities volunteered to participate. All of the workshops were performed at municipality facilities with municipal officials participating. The number of municipal officials that participated during the workshops varied between 2 and 10 persons and the number of researchers participating varied between two and three. The municipal officials that participated hade different roles relevant for the process that were analysed e.g. IT managers, assistants, administrators, register clerks. A high level official made the selection of participants from the municipalities at each municipality. Prior to the 
workshop the researchers had communicated the scope and aim for the workshops and asked the responsible high level official to include suitable persons. The agenda for each municipality were structured in the same way. First all participants presented themselves. The researchers presented their research area and their intentions with the meeting. Secondly the research project was presented and the advantages and disadvantages with the solution were discussed. Then the current municipal process for complaint and problem management were analysed by letting the officials describe their work tasks and in what order from receiving a complaint or problem to the case is finished. The identified tasks were written on post-its or on a white board, and notes were taken by the researchers. Thereafter the agenda ended with analysing the to-be process for complaints and problems with the app included as a new input channel. More workshops were conducted in some of the municipalities because it was more time consuming to go through the agenda in these municipalities. Table 1 shows a compilation of the involved municipalities and the number of workshops carried out at each municipality.

Table 1. Participating municipalities

\begin{tabular}{lcc}
\hline Municipality & Abbreviation & Number of workshops \\
\hline Municipality 1 & M1 & 3 \\
Municipality 2 & M2 & 3 \\
Municipality 3 & M3 & 1 \\
Municipality 4 & M4 & 1 \\
Municipality 5 & M5 & 2 \\
\hline
\end{tabular}

During the workshops discussions regarding issues related to business processes were brought to life. The participants made statements about perceived challenges related to business process management. Often the statements fuelled a discussion witch led to new statements. The researchers were passive during these discussions to minimize the risk of being leading. Also the challenges that the researchers encountered when analysing and modelling the processes were noted.

Apart from the workshops also documents (requirement specification for the CPR system, municipal routine description) and artifacts (case management systems and front end app) have been used as data.

In order to analyse the collected data all notes from each workshop were first discussed and compared by the researchers. The researchers then tried to model the processes in Visio following the notation of YAWL [13]. All data material related to process management challenges were then compiled and analysed, and challenges were derived by the researchers' interpretations. To create a better understanding and overall view the challenges were then categorized by using the labels of [12] six core elements of business process management. The reason for using this categorisation is that it encompasses all elements needed to provide a holistic understanding of BPM [12]. 


\section{$4 \quad$ Results}

In this section the results from the empirical study are presented. All challenges found and to which BPM core element the challenges relate to are compiled in table 2 . Then, each challenge is described and examples of how these challenges leads to inefficiencies in the daily work of municipal workers are given. If nothing else is explicitly written, a challenge is described if it was encountered in three or more municipalities.

Table 2. Process Management Challenges

\begin{tabular}{ll}
\hline BPM Core Element & Challenge \\
\hline Strategic Alignment & $\begin{array}{l}\text { Organisational structure, initiatives, legal aspects, politicians } \\
\text { and management agendas }\end{array}$ \\
Governance & Responsibilities, process owners, information management \\
Methods & No methods \\
Information Technology & Multiple IT systems, IT system integration, legacy systems, \\
& Proprietary systems \\
People & Routines, education \\
Culture & Responsiveness to change, resistance to change \\
\hline
\end{tabular}

\subsection{Strategic Alignment}

The organizational structure of the municipalities in isolated silos is not aligned with a process oriented approach. M4 explained that the social service unit functions as a world of its own. This causes insufficient insight and lack of relevant knowledge of other units regarding responsibilities and how they work. "No one sees the entirety, everyone only see their part" (M4). For example in M1 it happens that a submitted complaint is received by a unit not responsible for solving a complaint of that nature and the receiver doesn't know to what unit it should be forwarded. This has a negative impact on the effectiveness of handling the issue.

Functional silos also resulted in difficulties to perform process design. In four out of the five different municipalities involved in this research it was not possible to design a single complaint and problem management process. That was due to considerable differences in the work routines between the different administrative units.

Initiatives taken are not aligned with process management. E-service for complaints and problem reporting is designed in a way that could easily lead to misinterpretations by citizens. For example in M1 e-service for submitting complaints and problems the citizen needs to state the administrative unit that the issue will be sent to. The purpose is to simplify the administration of cases within the municipality. If the citizen chooses the wrong administrative unit when reporting, a case can "theoretically spin around a lot in the system between different administrative units" (M1).

In M5, they have implemented a customer service that is intended to work as a single point of contact where citizens can submit all types of cases. The customer service is not integrated with the municipality's complaint and problem management process, "it is a completely separate process" (M5). 
Management and politicians agendas are not always compatible and in Sweden elections are held every fourth year; theoretically a new political agenda might be the result of each local government election. Change of political agenda is something that can affect all municipalities in Sweden since the same political system applies. To what extent it poses a challenge is due to the differences in agendas and municipalities' ability to change. Only M3 and M5 explicitly mention this challenge by stating that management and political agendas don't always match.

Legal aspects and legislation changes complicate the routines at the municipalities. For example in M1, if a complaint about a mistreatment is submitted through their eservice the complaint is registered automatically in the system integrated with the eservice. This particular system doesn't meet the legal requirements of archiving cases that belong to the social welfare office. Therefore a mistreatment complaint needs to be manually registered in another cases management system that meets the legal requirements. Clearer laws regarding the municipalities' responsibilities to handle for example pupils being bullied at school such issues has to be archived correctly and therefore entered into a specific system. In M4 a new law that relate to care result in that the municipality need new fields in their case management system.

\subsection{Governance}

No clearly defined and communicated responsibilities are a challenge that cause inefficiencies in municipalities process management. M1 exemplifies that a register clerk forwards a submitted complaint or problem to the administrator that shall send a reply to the citizen. When the register clerk forwards the complaint or problem a confirmation that the message has been received with the administrators contact information is sent to the citizen. If it is unclear which administrator should answer the citizen and the issue is forwarded to the wrong administrator then the citizen may contact the wrong administrator. An issue might even be closed but continue to move around in the organization or an issue might be overlooked because of unclear responsibilities. $28.1 \%$ of the issues in M2 are initially sent to the wrong administrator.

No process owners have been present in any of the workshops with the municipalities nor have any of the municipal workers mentioned that a specific person is responsible for the complaint and problem management process. However, the researchers have noticed that some people take a lot of responsibility for the process, unofficial process ambassadors exist.

How information is managed is a challenge that causes uncertainties. M5 is experiencing uncertainties in what needs to be documented and it is perceived hard to get an overview when people store documents in their desk or in a file folder. M4 experiences that information is not spread throughout the entire municipality.

\subsection{Method}

During the workshops the researcher did not encounter any challenges related to methods nor did any of the municipalities mention anything about methods related to BPM. This could in itself be seen as a challenge, i.e. lack of methods for BPM. 
During the discussions about the complaint and problem management process none of the municipalities provided any reference process models.

\subsection{Information Technology}

All of the municipalities use multiple IT systems that are most often not integrated which cause manual tasks and overhead work. In M1 some cases has to be finished in one system and then registered manually in another system and sometimes cases are double registered. M1 exemplifies by describing when a registration of an illegal building are sent in by a user and registered automatically in the wrong system. The case is then finished in that system and instead the case needs to be manually initiated in the correct system. Another example from M1 is when a submitted case concerns a problem that needs to be fixed by an external provider an order cannot be created directly in the system, but needs to be created in a separate system. M1 describes their system for complaints and problems as an intermediate system and wishes for integration with other backend systems. In order to extract statistics on issue handling within M2, problems need to be registered in two different systems. M3 doesn't use the full potential in their systems; instead they buy new systems when functionality is needed. M3 states that "it is completely preposterous to buy new systems instead of developing what you already have". In M5 says that "we don't utilize our system to the fullest", instead we "buy different systems for different purposes and they have never been integrated".

Due to legacy systems and proprietary systems municipalities have trouble integrating systems. M1 and M2 describes that many municipalities have a closed environment; it makes it harder to integrate the system. M3 describes that they have old systems and that the providers doesn't provides specifications such as XML schemas. Legacy systems still running within municipalities doesn't have functional support for automation of tasks and the interfaces are difficult to use for infrequent users thus creating problem for administrative workers that do not receive issues frequently. "Our system is difficult to use and therefore the usage is not spread throughout the organization, only very few people use it" (M2). In M3, one of their IT systems is not compatible with windows 7 so they have to log on to a remote desktop, which creates "another window among many windows". Also, what the researchers realized when they got access to the different municipality IT systems is that many of the systems are not process oriented and does not support the work routines associated with the complaint and problem management handling.

\subsection{People}

Ad hoc routines and uncertainties in work routines are two people related challenges. Many administrative workers prefer to give answers directly to citizens contacting them and skip the registration of the issue in the case management system. It is not communicated through any system what issues are solved, instead messages about solved issues are e-mailed to one person in the organization, no one else knows about the status of issues (M2). In M3 not all administrators are using the case management 
system and if they answer something directly to a person they do not register it in the system. M5 stated that the have shortcomings in their administrative routines, they perceive uncertainties in how things should be handled. Deficiencies in routines are also emphasized through the following quotes: "I am guessing that we have a number of complaints, but they are probably stuck somewhere" (M5).

Citizens use communication channels that are not intended for submitting complaints and problems, e.g. in M1 citizens sends e-mails directly to the municipality workers e-mail instead of using channels that are connected to the case management system. Some citizens that frequently submit issues learn the administrators e-mail addresses and sends e-mails directly to them. "Some cases fall outside the system and it creates manual work" (M1).

Municipalities don't put effort into educating and gain approval by the ones affected when buying new IT systems. In M4 it is not communicated how new technology is supposed to be used. "People feel burned" (M4). M3, "the management commitment, the people and education are what are required for an IT system not to be a system on the shelf." In M2 only a few persons work with their case management systems because the usage is not spread throughout the organization.

\subsection{Culture}

Responsiveness and resistance to changes are challenges in municipalities. M4 worries that they might not be able to handle the change the CPR system will bring, since they perceive that there are constant changes and they cannot handle changes all the time. There are evidences of people in the municipalities seeing process management as something with potential: "That everything is connected is important, that you see the complete picture and not only the work that you do" (M2). They see the need but have difficulties responding to it. "The negative thing about this integrated application is that we have to get resources to handle issues from this new channel. We cannot create an information flow that we are not prepared to handle and we should not implement the channel before we are ready. We are not there yet, we are not ready." (M2).

\section{Conclusion}

This paper has identified challenges within all of the six core elements of BPM strategic alignment, governance, methods, information technology, people and culture [12]. The results show that municipalities are still being organized by functions and therefore the organizational structures of municipalities are not aligned with a process oriented approach. Poorly defined and communicated responsibilities are another governance challenge that causes inefficiencies in municipalities' process management. No methods supporting process management exist. Municipalities are also facing challenges related to information technology such as usage of multiple IT systems, IT system integration, legacy and proprietary IT systems. Challenges related to the people working with the process using various ad hoc routines and not being 
sufficiently educated were also found. Notable challenges found related to culture are responsiveness to change and resistance to change. For the researchers many of these challenges contributed to the difficulty of creating a uniform view of the process and to determine a best practice process for complaints and problems management. IT (a process and an artifact) was used as an enabler (door opener) to stimulate and fuel the exposure of the challenges. It was a successful approach for starting a change dialogue because the municipal workers had a willingness to collaborate and change, and also showed openness to adopt the new IT artifact.

The results imply that process management maturity in Swedish municipalities is low. Municipalities are struggling with taking the first small steps in re-organizing according to process-logic, despite visions from politicians and despite Sweden being ranked high in e-government development. Similar empirical evidence has been identified in previous research [18-20, 22-26].

For academia this paper informs about the low maturity within Swedish municipalities in regards to process management. It complements existing studies and provides a contemporary view of process management challenges. The paper also provides valuable insights of challenges that need to be address and can be used to position future research. This paper strengthen findings regarding low BPM maturity in local government found in other countries examples are [26] in Germany and [25] in Brazil.

For practice this paper contributes in providing an understanding of identified challenges giving examples of how business process challenges leads to inefficiencies in the daily work of municipal workers. The approach to use an IT artefact to fuel discussion and implement change was deemed usable when rationalising processes and improving process maturity within the public sector. This approach should therefore be taken into consideration by public management when initiating change within municipalities. Business process initiatives within municipalities should take a holistic perspective of process management since challenges were found in all core elements of BPM. The researchers also see the need for municipalities to get a bottom up support by complementing e-government policies and guidelines with instructions on how they can be implemented at a local level e.g. instructions of how single public processes can be transformed to promote e-government. Today e-government is promoted by a top-down approach were abstract policies and guidelines are communicated towards municipalities' and they have to implement them on their own.

Limitations of this study that affects the transferability of the findings are that the municipalities' were not randomly selected and that only Swedish municipalities were studied. However the author argues that it is reasonable that the results are transferable to other local governments in other countries due to similarities in the result of earlier related studies (see above). Also, this paper does not consider cross sectional variance; that is how the challenges are influenced by differences between the municipalities and the study is limited to the investigation of BPM related challenges.

We propose future research to focus on strategies for how to overcome identified challenges and present a structured framework with challenges and success factors. Also building collaborative solutions together with private partners should be investigated. 
Acknowledgements. The author would like to thank the Swedish Governmental Agency for Innovation Systems and NordForsk for founding the research project.

\section{References}

1. Moon, M.J.: The Evolution of E-Government among Municipalities: Rhetoric or Reality. Public Administration Review 62(4), 424-433 (2002)

2. Beynon-Davies, P.: Constructing electronic government: the case of the UK inland revenue. International Journal of Information Management 25, 3-20 (2005)

3. United Nations.: UN E-Government Survey 2012: E-Government for the People. United Nations, New York (2012), http://unpan1.un.org/intradoc/groups / public/documents/un/unpan048065.pdf

4. SAFAD.: The 24/7 Agency Criteria for 24/7 Agencies in the Networked Public Administration (2000), http://www.statskontoret.se/publikationer/2000/ the-247-agency-criteria-for-247-agencies-in-the-networkedpublic-administration-/

5. Regeringskansliet.: Handlingsplan för eFörvaltning. Nya grunder för IT-baserad verksamhetsutveckling i offentlig förvaltning (2008), http://www.sweden.gov.se/ content/1/c6/09/65/12/4ffd1319.pdf

6. Regeringskansliet.: Statens offentliga utredningar. Strategi för myndigheternas arbete med eförvaltning (2009) (in Swedish), http://www.regeringen.se/sb/d/11456/a/ 133813

7. Regeringskansliet:: It i människans tjänst - en digital agenda för Sverige (2011), http: / /www.regeringen. se/content/1/c6/17/72/56/5a2560ce.pdf

8. EU: Ministerial Declaration on eGovernment (2009), http://www. egov2009.se/ wp-content/uploads/Ministerial-Declaration-oneGovernment.pdf

9. Nilsson, A., Uppstöm, E.: Modeling IT-mediated value encounters between citizens and local government. In: International Conference of Service science. Management and Engineering (2012)

10. Davenport, T., Short, J.: The New Industrial Engineering: Information Technology and Business Process Redesign. Sloan Management Review 31(4), 11-27 (1990)

11. Kohlbacher, M.: The Effects of Process Orientation on Customer Satisfaction. Product Quality and Time-based Performance (2009)

12. Rosemann, M., Brocke, J.V.: The Six Core Elements of Business Process Management. In: van Brocke, J., Rosemann, M. (eds.) International Handbook on Business Process Management 1 - Introduction, Methods, and Information Systems, pp. 107-122. Springer, Heidelberg (2010)

13. ter Hofstede, A.H.M., van der Aalst, W.M.P., Adams, M., Russell, N.: Modern Business Process Automation: YAWL and its Support Environment. Springer, Berlin (2010)

14. van der Aalst, W.M.P., ter Hofstede, A.H.M., Weske, M.: Business Process Management: A Survey. In: van der Aalst, W.M.P., ter Hofstede, A.H.M., Weske, M. (eds.) BPM 2003. LNCS, vol. 2678, pp. 1-12. Springer, Heidelberg (2003)

15. Corradini, F., Falcioni, D., Polini, A., Polzonetti, A., Re, B.: Designing quality business processes for E-government digital services. In: Wimmer, M.A., Chappelet, J.-L., Janssen, M., Scholl, H.J. (eds.) EGOV 2010. LNCS, vol. 6228, pp. 424-435. Springer, Heidelberg (2010) 
16. Corradini, F., Falcioni, D., Polini, A., Polzenetti, A., Re, B.: Improving e-Government Business Processes Applying Formal Verification. In: 4th International Conference on Methodologies, Technologies and Tools Enabling e-Government, pp. 33-44 (2010)

17. Gong, Y., Janssen, M.: From policy implementation to business process management: Principles for creating fexibility and agility. Government Information Quarterly 29(1), 6-71 (2012)

18. Indulska, M., Chong, S., Bandara, W., Sadiq, S., Rosemann, M.: Major Issues in Business Process Management: An Australian Perspective. In: Spencer, S., Jenkins, A. (eds.) Proceedings of the 17th Australasian Conference on Information Systems, Australia, South Australia, Adelaide, December 6-8 (2006)

19. Bandara, W., Indulska, M., Chong, S., Sadiq, S.: Major Issues in Business Process Management: An Expert Perspective. In: Proceedings ECIS 2007 - The 15th European Conference on Information Systems, St Gallen, Switzerland, pp. 1240-1251 (2007)

20. Sadiq, S., Indulska, M., Bandara, W., Chong, S.: Major Issues in Business Process Management: A Vendor Perspective. In: Proceedings 11th Pacific Asia Conference on Information Systems, Auckland, New Zealand, pp. 40-47 (2007)

21. Palmberg, K.: Experiences of implementing process management: a multiple-case study. Business Process Management Journal 16(1), 93-113 (2010)

22. Weerakkody, V., Baire, S., Choudrie, J.: E-Government: The Need for Effective Process Management in the Public Sector. In: Proceedings of the 39th Annual Hawaii International Conference on System Sciences, Hawaii (2006)

23. Indulska, M., Recker, J.C., Rosemann, M., Green, P.: Business process modeling: current issues and future challenges. In: The 21st International Conference on Advanced Information Systems, Amsterdam, The Netherlands, June 8-12 (2003)

24. van der Aalst, W.M.P.: Challenges in business process management: Verification of business processes using Petri nets. Bulletin of the EATCS (80), 174-199 (2003)

25. Valenca, G., Alves, C., Santana, A., Oliveira, J., Santos, H.: Understanding the adoption of BPM governance in Brazilian public sector. Paper accepted for Inclusion in the Proceeding of the 21st European Conference on Information Systems (2013)

26. Niehaves, B., Plattfaut, R.: From bureaucratic to quasi-market environments: On the coevolution of public sector business process management. In: Wimmer, M.A., Chappelet, J.-L., Janssen, M., Scholl, H.J. (eds.) EGOV 2010. LNCS, vol. 6228, pp. 387-399. Springer, Heidelberg (2010)

27. Lönn, C.-M., Uppström, E., Wohed, P., Juell-Skielse, G.: Configurable process models for the Swedish public sector. In: Ralyté, J., Franch, X., Brinkkemper, S., Wrycza, S. (eds.) CAiSE 2012. LNCS, vol. 7328, pp. 190-205. Springer, Heidelberg (2012)

28. Myers, M.D.: Qualitative Research in Business \& Management. SAGE Publications (2009) ISBN 978-1-41292165-7

29. Yin, R.K.: Case study research: Design and methods, 3rd edn. Sage, Thousand Oaks (2003)

30. Juell-Skielse, G.: Enhancing Complaint and Problem Management: Designing and Evaluation of an M-Service Using Pictures and Positioning. International Journal of E-Services and Mobile Applications 2(2) (2010) 